\title{
Distribution of selected elements in atherosclerotic plaques of apoE/LDLR-double knockout mice assessed by synchrotron radiation-induced micro-XRF spectrometry
}

\author{
M. Gajda, ${ }^{1 *}$ K. Banaś, ${ }^{2}$ A. Banaś, ${ }^{2}$ J. Jawień, ${ }^{3}$ Ł. Mateuszuk, ${ }^{3}$ S. Chłopicki, ${ }^{3}$ W. M. Kwiatek, ${ }^{2}$ \\ T. Cichocki ${ }^{1}$ and G. Falkenberg ${ }^{4}$ \\ 1 Department of Histology, Jagiellonian University Medical College, Kopernika 7, 31-034 Kraków, Poland \\ ${ }^{2}$ Institute of Nuclear Physics, Radzikowskiego 152, 31-342 Kraków, Poland \\ ${ }^{3}$ Department of Experimental Pharmacology, Chair of Pharmacology, Jagiellonian University Medical College, Grzegórzecka 16, 31-531 Kraków, \\ Poland \\ ${ }^{4}$ DESY, Notkestra $\beta$ e 85, D-22607, Hamburg, Germany
}

Received 23 June 2007; Accepted 21 March 2008

\begin{abstract}
Apolipoprotein E and LDL receptor double-knockout (apoE/LDLR ${ }^{-1-}$ ) mice represent a reliable experimental model of atherosclerosis. The aim of the present study was to examine the elemental content of atherosclerotic plaques using synchrotron radiation-induced micro $x$-ray fluorescence (XRF) spectrometry. Numerous essential and trace elements were detected in cross-sections of aortic roots collected from 6-month-old apoE/LDLR ${ }^{-1-}$ mice fed with chow diet. Two-dimensional maps of the elemental distribution and point recordings were compared with images of consecutive sections stained histologically, allowing precise localization of the analyzed elements in morphologically defined areas of aortic lesion. The sulphur was detected in areas occupied by macrophages and smooth muscle cells. Iron was observed in high concentrations in cardiac and smooth muscle, blood clots and in adjacent coronary vessels. Lower concentrations of iron were seen in the regions of plaques rich in macrophages and lipids. Copper was detected in higher amounts only in cardiac muscle and its concentration in plaques was very low. There was a quite high content of calcium in aortic plaque areas containing lipids and macrophages. Much higher concentrations of calcium were observed in mineral deposits, mostly located in the aortic media. Similar distribution was also characteristic for phosphorus. Zinc was observed in moderately low concentrations in atheromas. Higher content of zinc was seen in smooth musculature, in cardiac muscle and in mineral concretions. The presented results provide a substantial morphological and physicochemical background for further investigations aiming to evaluate pharmacological and dietary treatment of atherosclerosis in an apoE/LDLR ${ }^{-1-}$ mouse model. Copyright $\odot 2008$ John Wiley \& Sons, Ltd.
\end{abstract}

\section{INTRODUCTION}

Nowadays, atherosclerosis is the single largest cause of mortality in westernized human populations but still the pathomechanism of this disease is not entirely understood. ${ }^{1}$ It has been proposed that atherosclerosis is a multietiological inflammatory and degenerative disease, related not only to cholesterol overload. Various events, including endothelial dysfunction, accumulation of circulating low density lipoproteins (LDL) within arterial walls, and nonenzymatic oxidation of LDL molecules lead to activation and migration of blood-borne inflammatory and immune cells, mainly macrophages, mast cells and T lymphocytes. Macrophages, phagocytosing lipids, become foam cells, and together with lipid debris form a core of atherosclerotic lesion (atheroma). Cytokines produced by atheroma cells stimulate

*Correspondence to: M. Gajda, Department of Histology, Jagiellonian University Medical College, Kopernika 7, 31-034 Kraków, Poland. E-mail: mmgajda@cyf-kr.edu.pl proliferation and migration of smooth muscle cells from media of the vessel to the intima, and they also accelerate production of collagen fibers by smooth muscle cells and local fibroblasts. Metalloproteinases, released from almost all cell types present in the plaque, are responsible for degradation of components of the extracellular matrix and its reorganization. Smooth muscle cells and collagen fibers form a 'fibrous cap' at the adluminal face of the atheroma, stabilizing a lesion and protecting it against rupture.

All the mentioned components, including cells and extracellular material, can be demonstrated histologically in atherosclerotic lesions in apolipoprotein $\mathrm{E}$ (apoE)knockout, and in apoE and LDL receptor double-knockout (apoE/LDLR ${ }^{-/}$) mice. ${ }^{2,3}$ ApoE/LDLR ${ }^{-/-}$mice represent a new animal model that spontaneously develops severe hyperlipidemia and atherosclerotic plaques. ${ }^{4}$ It has been reported that the advancement of atherosclerosis is markedly superior in apoE/LDLR ${ }^{-/-}$mice than in mice deficient in apoE alone..$^{5}$ Thus, an apoE/LDLR ${ }^{-/-}$mouse is considered 
as one of the best animal models to study the composition and mechanisms of the development of atherosclerotic plaques.

Surprisingly, in contrast to extensive literature related to the pathomechanism of atherosclerosis in mice, the distribution of elements in atherosclerotic plaques of genetargeted animals has not been comprehensively analyzed. Synchrotron microprobes, offering high sensitivity and good resolution, enable nondestructive analysis of essential and trace elements in biological samples, even at the cellular level. Synchrotron radiation-induced $x$-ray fluorescence (XRF) was successfully applied to examine histological sections derived from neoplasms, degenerative lesions of the central nervous system and others. ${ }^{6,7}$ The use of this technique in atherosclerosis research was limited to 3-D imaging of vessels involved in the pathological processes. ${ }^{8}$

In the present study, we have combined synchrotron radiation micro-XRF spectrometry with a complete set of histological stainings to determine localization and concentration of selected elements in histologically defined areas of atherosclerotic lesions in aortic roots of apoE $/ \mathrm{LDLR}^{-/-}$mice.

\section{METHODS}

\section{Animals and treatment}

Ten female apoE ${ }^{-/-} / \mathrm{LDLR}^{-/-}$mice on the mixed C57BL/6J $\times 129 /$ SvJ background were obtained from Taconic (Ejby, Denmark). Mice were housed in $12 \mathrm{~h} / 12 \mathrm{~h}$ light/dark cycle in air-conditioned rooms $\left(22.5 \pm 0.5^{\circ} \mathrm{C}, 50 \pm 5 \%\right.$ humidity) and they had an unlimited access to water and standard chow diet.

Six-month-old mice were sacrificed by intraperitoneal administration of sodium thiopental (Vetbutal, Biowet, Puławy, Poland; $100 \mathrm{mg} / \mathrm{kg}$ b.w.). National and international principles of laboratory animal care were followed and all procedures were approved by and conformed to guidelines of the Jagiellonian University Animal Experimentation Ethics Committee.

\section{Specimen preparation}

In anesthetized mice, the thorax was longitudinally opened, right atrium was incised, and the heart was perfused with phosphate-buffered saline (PBS, $\mathrm{pH}=7.4$ ) through the apex of the left ventricle. The heart was dissected out, rinsed with PBS, embedded in OCT compound (Cell Path, Oxford, UK) and snap-frozen. Blocks were mounted on cryostat holders and $10-\mu \mathrm{m}$-thick sections were cut at $-20^{\circ} \mathrm{C}$ according to a standardized protocol (for details see ${ }^{9}$ ). Briefly, serial sections from the proximal $1 \mathrm{~mm}$ of the aortic root were collected on separate slides, air dried and fixed in acetone (immunohistochemistry) or $4 \%$ phosphate-buffered paraformaldehyde (other stainings). Sections subjected to micro-XRF examination were cut at $-20^{\circ} \mathrm{C}$, mounted on 2.5$\mu \mathrm{m}$-thick Mylar foil, freeze-dried and left unfixed. From each animal, six specimens from different levels of the aortic root (100-um intervals) were used for microprobe examination. Adjacent sections were stained as described below.

\section{Histological and immunohistochemical stainings}

For complete morphological description, consecutive sections were stained to visualize specific components present in atherosclerotic plaques: with oil red-O(ORO) for lipids, Masson's trichrome for collagen fibers and cellular components, orcein for elastic fibers, alcian blue for matrix proteoglycans and von Kossa impregnation for mineral deposits.

Indirect double immunofluorescence staining for CD68 and $\alpha$-smooth muscle actin (SMA) allowed simultaneous detection of macrophages and smooth muscle cells, respectively $\left(\right.$ see also $\left.^{10}\right)$. The sections were incubated overnight at room temperature in humid chambers with mixture of primary antibodies: Cy3-conjugated anti-SMA (Sigma Aldrich, St. Louis, MO, \#C6198; diluted 1:600) and rat antimouse CD68 (Serotec, Oxford, UK, \#MCA1957XZ; diluted 1:800). Then, goat antirat IgG biotinylated serum (diluted 1:800) followed by DTAF-conjugated streptavidin (diluted 1:500; both from Jackson IR, West Grove, PA) were applied. Finally, sections were mounted in glycerol-PBS $(\mathrm{pH}=8.6)$.

\section{Microscopic examination}

Histologically stained sections were examined in transmitted light under an Olympus BX50 microscope (Olympus, Tokyo, Japan). The same microscope equipped with mercuric burner and filter sets: U-MNG and U-MNIBA for detection of Cy3 (red) and DTAF (green) fluorescence, respectively, was used to examine immunofluorescence. Images of the aortic roots were recorded using Olympus DP71 digital CCD camera and stored as TIFF files.

\section{XRF setup and measurements}

All micro-XRF measurements were carried out at beamline $\mathrm{L}$ of the storage ring DORIS III at HASYLAB (DESY, Hamburg, Germany). The DORIS III synchrotron light source operates at an electron energy of $4.45 \mathrm{GeV}$, providing a critical $\mathrm{x}$-ray energy of $16.04 \mathrm{keV}$. The maximum ring current is $140 \mathrm{~mA}$. The micro-XRF examination was conducted in the air. Measured samples were mounted on a remotely controlled stage equipped with high-precision stepping motors allowing micrometric movement in $x y z$ space. A video microscope (magnification $200 \times$ ) was used to control positioning of the sample. A sample was placed at $45^{\circ}$ angle to the beam axis. The primary photon energy was set to $18 \mathrm{keV}$ by a multilayer double monochromator. A polycapillary half-lens was used for beam focusing, hence the final beam size on the sample was approximately $15 \mu \mathrm{m}$ in diameter. Emitted elemental spectra were recorded with $\mathrm{Si}(\mathrm{Li})$ semiconductor detector. Two types of recordings were obtained from the analyzed sections. Two-dimensional maps were acquired from areas encircling the entire aortic root with surrounding cardiac muscle (resolution $15 \mu \mathrm{m}$, about 10000 spectra from area about $1.5 \times 1.5 \mathrm{~mm}$, time of acquisition $3 \mathrm{~s}$ from each point). From morphologically defined areas precise point spectra were recorded (resolution $15 \mu \mathrm{m}$, time of acquisition $300 \mathrm{~s}$ ). The obtained spectral data was processed and distribution maps were generated employing a nonlinear least square fitting strategy with the use of AXIL software, Linux version (for details see ${ }^{11}$ ). Measurements of external standards (gelatine-embedded reference materials) were used to determine dry mass concentrations of the elements in the analyzed samples (expressed in $\mu \mathrm{g} / \mathrm{g}$ ). Differences of elemental concentrations between distinct morphological 
regions were tested with Mann-Whitney U Test (KyPlot 2.0, KyensLab, Tokyo, Japan) and $p<0.05$ was considered statistically significant.

\section{RESULTS}

\section{Histology}

As demonstrated by ORO staining, aortic roots of 6-monthold apoE/LDLR ${ }^{-/-}$mice fed with chow diet displayed very intense accumulation of lipids in the intima of the vessel marking locations of atherosclerotic lesions (Fig. 1(a)). Moreover, fatty streaks were seen in adjacent coronary arteries and even in the pulmonary trunk. A very weak alcian blue staining was observed in the aortic root, confined only to regions closest to the valve attachments (data not shown). Masses of macrophages revealed by CD68 immunostaining were seen in the lesions, at least partially overlapping the areas labeled by ORO (Fig. 1(c)). CD68-immunopositive cells were not only located in the shoulders of atherosclerotic lesions but they were also abundant in the central (major) region of the plaque. Collagen fibers were abundantly present in lesions, rather than in areas not occupied by lipids and macrophages (Fig. 1(b)). There were almost no elastic fibers in atherosclerotic plaques, although elastin was abundant in the elastic laminae forming media of the vessel (data not shown). SMA immunoreactivity was seen in normal smooth muscle cells present in the media of the aortic root (media), and also in smooth muscle cells that migrated to or were newly formed near the surface of the atherosclerotic lesion (intima). In lesions, SMApositive cells were mostly found at the adluminal face of the vessel (Fig. 1(c)). Von Kossa impregnation revealed multiple calcifications localized mostly on the outer border of the plaque or within media (data not shown). Additionally, fine mineral deposits were clearly seen on the leaflets of the aortic valve.

\section{Elemental content}

Application of micro-XRF methods allowed to obtain precise elemental spectra demonstrating differences in concentrations of the analyzed elements in distinct areas of the observed lesions. The spectrum illustrative for typical region of the core of the plaque (containing lipids and macrophages) is depicted in Fig. 2(a), and for calcium deposit in Fig. 2(b).

Two-dimensional maps of the elemental distribution were compared to images of consecutive sections stained histologically resulting in precise localization of the analyzed elements in defined morphological structures. The distributions of such elements like potassium (Figs 1(h), 3(f)), chlorine (Figs 1(e), 3(c)) and rubidium (Fig. 3(h)) corresponded well with histological structure of the section and they were found in regions occupied by cells. Bromine showed relatively high accumulation only in normal smooth musculature of the aorta (Fig. 3(a)). Its concentration in smooth muscle cells in atherosclerotic plaques (intima) was
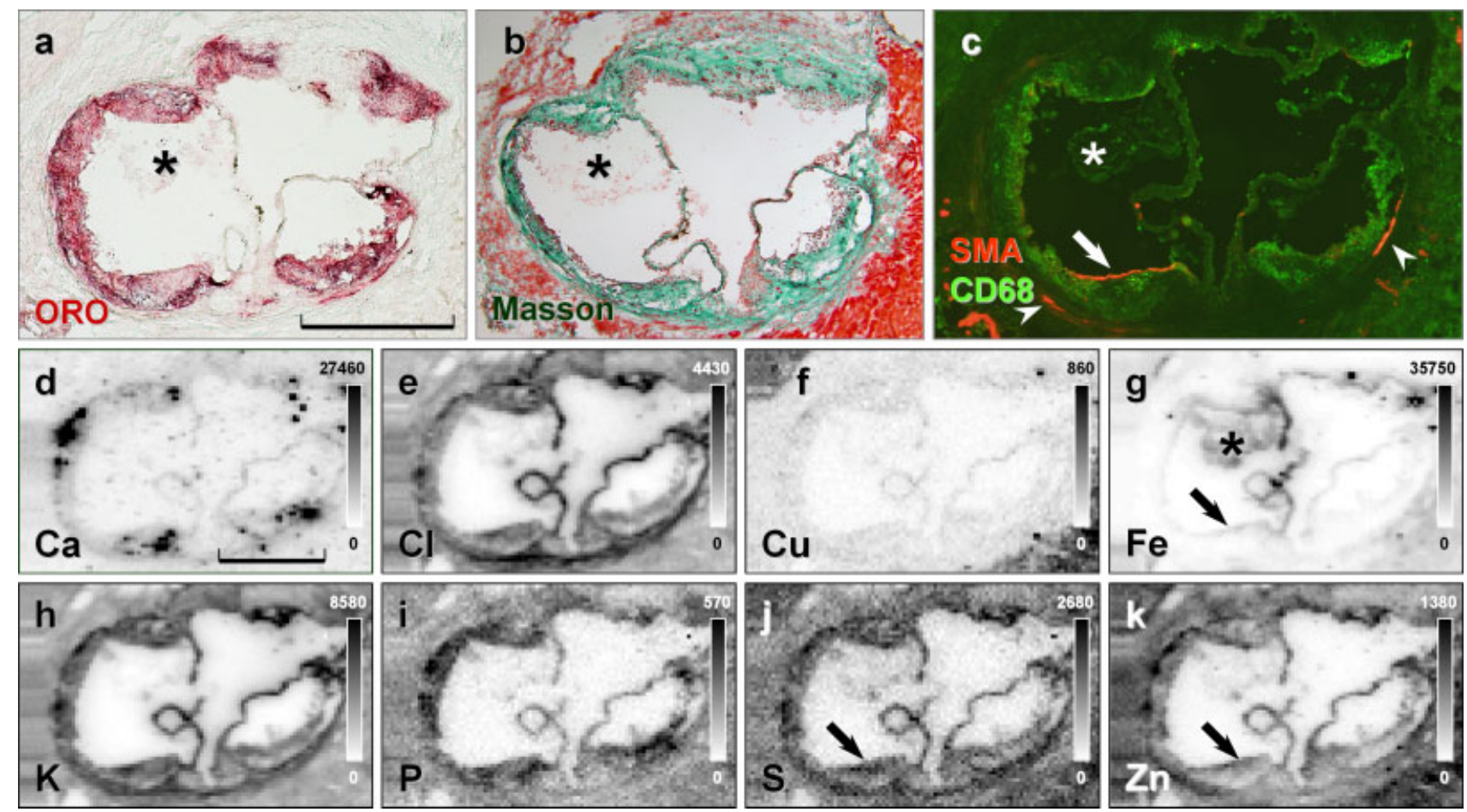

Figure 1. Consecutive sections of aortic root of apoE/LDLR ${ }^{-/-}$mouse stained with oil red-O (a), Masson's trichrome (b) and double-immunostained for smooth muscle actin (red) and CD68 (green) (c). General distributions of calcium (d), chlorine (e), copper $(\mathrm{f})$, iron (g), potassium (h), phosphorus (i), sulphur (j) and zinc (k) obtained by micro-XRF in adjacent section ( $d-k)$. Atherosclerotic plaques are labeled with oil red-O (a), smooth muscle cells are present in media (c, arrowheads) and in intima (c, arrow). Notice high accumulation of Fe, S, Zn in intimal smooth muscle (arrows in g, j, k). Collagen fibers are stained green in Masson's trichrome (b). Blood clot (asterisk) present in the aortic lumen shows very high concentration of iron (g). Scale bars $=500 \mu \mathrm{m}$. Gray-scale intensity bars show numbers of counts. 

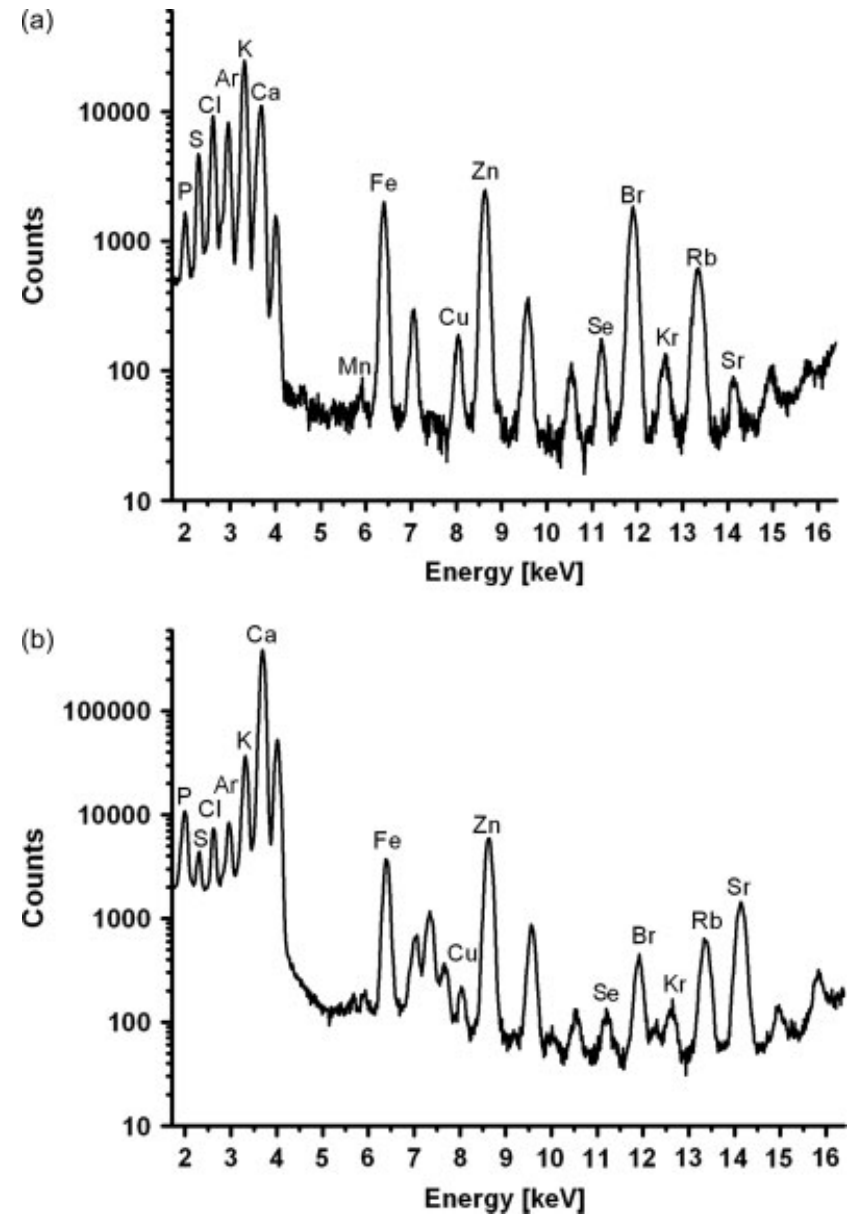

Figure 2. Representative elemental spectra obtained from point recordings in atheroma core containing lipids and macrophages (a) and in mineral deposit (b). Ar and $\mathrm{Kr}$ peaks come from the air.
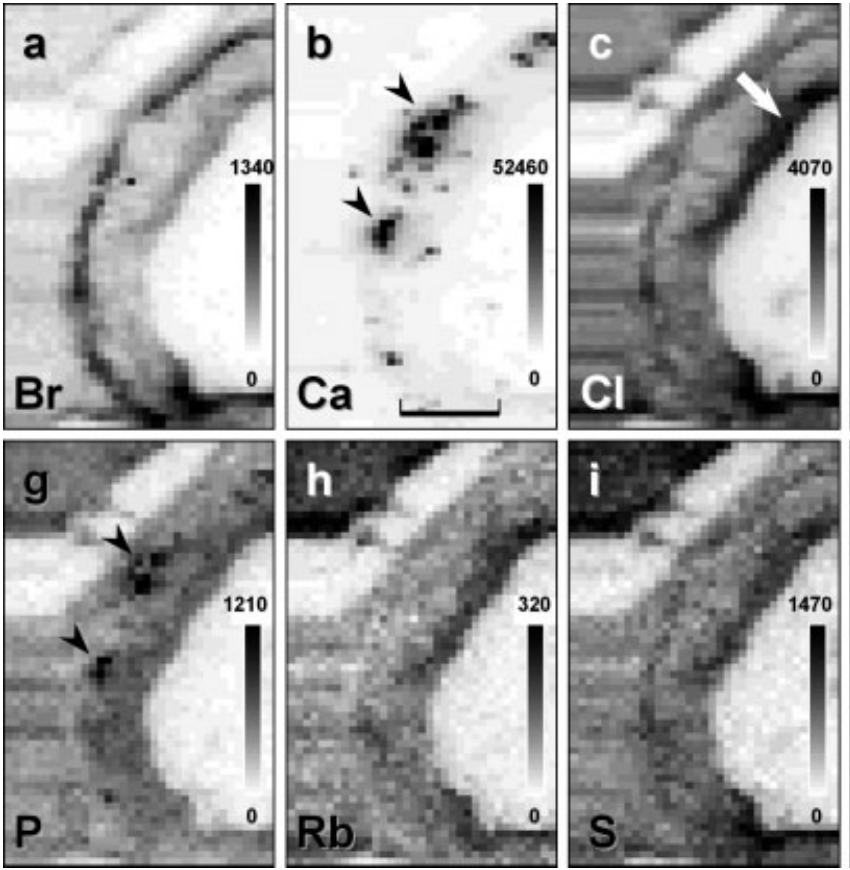

lower, although the difference was not statistically significant $(p>0.05)$. Sulphur content in atheromas was rather low and its presence was almost exclusively detected in areas occupied by macrophages and smooth muscle cells (Figs 1(j), 3(i)). Iron, abundantly present in adjacent cardiac muscle, was observed in high concentrations in smooth muscles (both, in media and intima) and in coronary vessels (Figs 1(g), 3(e)). Moderate, but lower than in the muscles, concentrations of iron were observed in the regions of the plaque rich in macrophages and lipids $(p<0.05)$. Unfortunately, very high amounts of iron were also seen in blood clots occurring in aortic lumen and they were mostly attached to valve leaflets (Fig. 1(g)). Copper was present in high amounts only in cardiac muscle (Figs 1(f), 3(d)) and its concentration in plaques was much lower $(p<0.005)$. There was quite a high content of calcium in aortic plaque areas occupied by lipids and macrophages (Figs 1(d), 3(b)). Dramatically higher (even up to 50 times more than in atheromas) concentration of calcium was observed in mineral deposits $(p<0.005)$. Similar distribution was also characteristic for phosphorus (Figs 1(i), 3(g)), however, its concentration difference between calcifications and atheromas was not so striking as it was in the case of calcium ( $p<0.05$ ). Strontium (Fig. 3(k)) and cadmium (not shown) were detected in mineral deposits as well, although their concentrations were very low. In lipid and macrophagecontaining areas, zinc (Figs 1(k), 3(1)) was observed at lower concentration than that seen in smooth musculature, in cardiac muscle and in mineral concretions $(p<0.005)$. Selenium was observed in very low concentrations in cell-rich areas of atherosclerotic lesion (Fig. 3(j)).

Since the measurements were performed in the air, argon and krypton peaks observed in elemental spectra come from the environment (Fig. 2).

Figure 3. Distribution of bromine (a), calcium (b), chlorine (c), copper (d), iron (e), potassium (f), phosphorus (g), rubidium (h), sulphur (i), selenium (j), strontium (k) and zinc (l) in atherotic plaque. Notice high accumulation of $\mathrm{Fe}, \mathrm{Zn}, \mathrm{K}, \mathrm{Cl}$ in intimal smooth muscle cells of the plaque (arrows), much higher concentrations of $\mathrm{Ca}, \mathrm{P}, \mathrm{Sr}$ in mineral deposits (arrowheads), and high level of $\mathrm{Cu}$ in cardiac muscle (asterisk). Scale bar $=200 \mu \mathrm{m}$. Gray-scale intensity bars show numbers of counts. 
The proportion of the weight concentrations of calcium to phosphorus was calculated in mineral deposits where $\mathrm{Ca} / \mathrm{P}$ ratio differed from 2.25 to 6.83 (mean $4.76 \pm 1.81$ ).

Comparisons of the concentrations $(\mu \mathrm{g} / \mathrm{g})$ of selected elements $(\mathrm{Ca}, \mathrm{Cl}, \mathrm{Cu}, \mathrm{Fe}, \mathrm{K}, \mathrm{P}, \mathrm{S}, \mathrm{Zn})$ are presented in Fig. 4.

\section{DISCUSSION}

Several physical methods have been used so far to evaluate the content of atherosclerotic plaque. For example, Raman
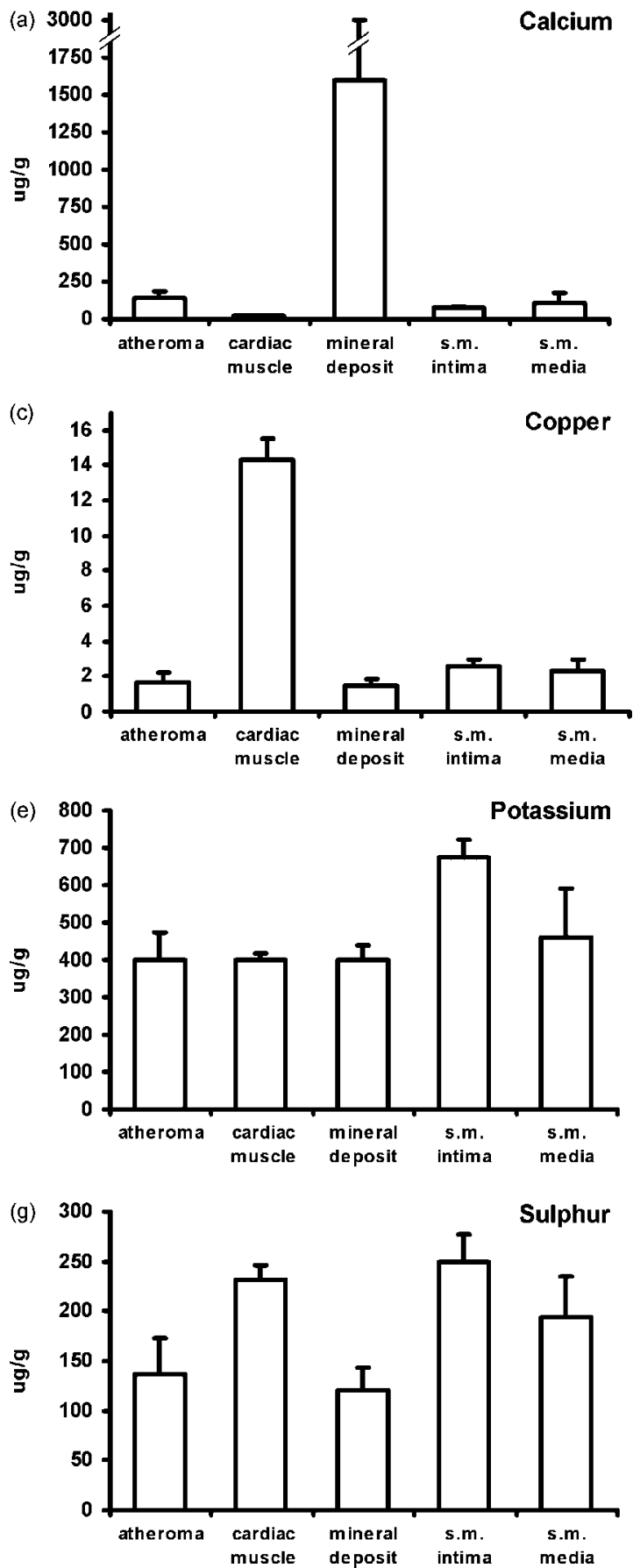

spectroscopy was employed to quantitatively study the size and distribution of cholesterol deposits and calcifications in $\mathrm{APOE}^{*} 3$-Leiden transgenic mice. ${ }^{12}$ Electron paramagnetic resonance (EPR) spectroscopy and inductively coupled plasma mass spectroscopy (ICPMS) were applied to estimate iron and copper content in human atherosclerotic plaques. ${ }^{13}$ Recently, Zhang and coworkers used XRF spectrometry to determine $\mathrm{Fe}, \mathrm{Cu}$ and $\mathrm{Zn}$ contents in several organs of transgenic mice expressing the familial Alzheimer's disease gene. $^{14}$
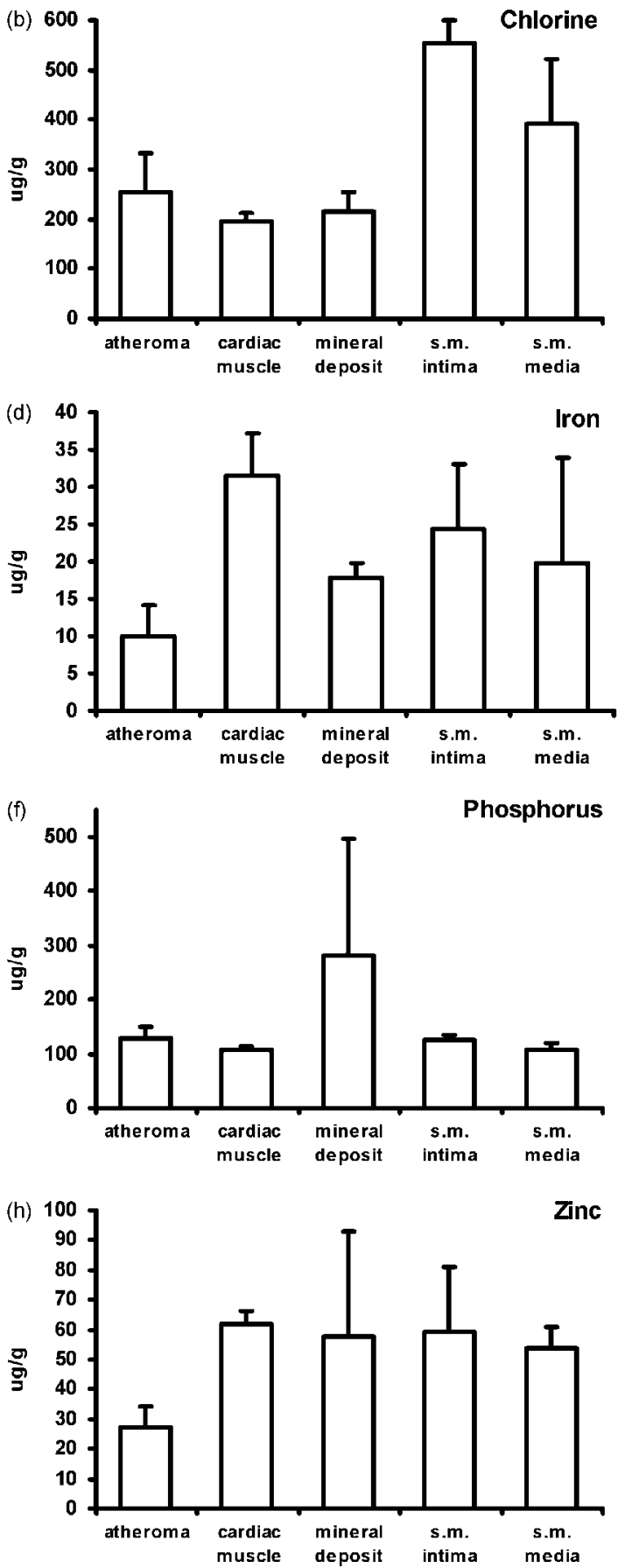

Figure 4. Concentrations (dry mass, means $\pm S D$ ) of calcium (a), chlorine (b), copper (c), iron (d), potassium (e), phosphorus (f), sulphur $(\mathrm{g})$ and zinc $(\mathrm{h})$ in morphologically defined areas of atherosclerotic plaques. Values obtained from point measurements in atheroma $(n=31)$, cardiac muscle $(n=21)$, mineral deposits $(n=19)$, smooth muscle in intima $(n=12)$, smooth muscle in media $(n=19)$. s.m., smooth muscle. 
In the present study, to our knowledge for the first time, we used synchrotron radiation micro-XRF setup to comprehensively quantify concentrations of several elements in histologically defined areas of atherosclerotic lesions in apoE/LDLR ${ }^{-/-}$mice. These animals represent a unique and reliable model of experimental atherogenesis that allows to investigate the antiatherosclerotic activity of classic and novel pharmacological compounds. ${ }^{10,15,16}$ Synchrotron radiation microprobes provide excellent sensitivity that enable detection of trace elements even in 'parts per million' amounts. High energy and intensity of synchrotron light used in the study allowed detection of a broad range of elements present in biological materials. Our setup, characterized by spatial resolution of $15 \mu \mathrm{m}$, was not efficient enough to demonstrate elements on cellular/subcellular level. However, cells and extracellular components in atherosclerotic lesions occupy larger areas, and it was not the aim of this study to examine elemental content of single cells.

Trace and essential elements are components of natural macromolecules, mostly proteins. The occurrence of elements in the analyzed structures was mostly related to their presence in certain proteins or to their spontaneous accumulation in tissues. Some trace elements, especially in a free form, were shown to have ability to oxidize biomolecules. ${ }^{17}$ In the light of inflammatory theory of atherogenesis, iron enhances endothelial cell activation in response to cytomegalovirus or Chlamydia pneumoniae infection. ${ }^{18}$ A potential mechanism for arterial wall damage by iron involves modifications of LDL, the major carrier of blood cholesterol. Many lines of evidence suggest that LDL, an important risk factor for atherosclerosis, must be oxidatively modified to recruit and activate inflammatory and immune cells. ${ }^{19}$ Metal-dependent oxidation reactions have been shown to occur in vitro. Iron induces lipid peroxidation in cultured macrophages and increases their ability to oxidize LDL. ${ }^{20}$ Cultured smooth muscle cells use extracellular iron to modify LDL, while some metal chelators inhibit LDL oxidation. ${ }^{17}$ Progression of atherosclerosis in cholesterol-fed rabbits was inhibited by treatment with the iron chelator, desferrioxamine. ${ }^{21}$ Anemia attenuated atherosclerosis, while erythropoietin-induced elevation of hematocrit enhanced atherosclerosis in apoE-deficient mice. ${ }^{22}$ Micromolar concentrations of iron and copper led to oxidization of LDL in cultures of smooth muscle cells and, subsequently, macrophages took up and esterified the cholesterol from modified LDL more extensively than from intact lipoprotein. ${ }^{23}$ Furthermore, iron can directly interact with blood platelets, resulting in their activation, thus promoting arterial thrombosis. ${ }^{24}$ In case of atherogenesis, however, the effect of iron is unclear and the relevant results are contradictory. In some investigations, iron-deficient diet reduced atherosclerotic lesions in apoE-deficient mice, whereas in others, a similar effect was achieved after iron overload..$^{25,26}$

According to our observations, iron was abundantly present in cardiac muscle mostly due to high amount of myoglobin in cardiomyocytes and the presence of numerous capillaries. In the aortic root, iron was seen in high concentrations in smooth muscle cells, both in media and in intima, probably because of its occurrence in smooth muscle myoglobin. Its concentration in atheromas was lower than in the surrounding areas. Opposite results were reported in early aortic plaques of rabbits fed on a highcholesterol diet. ${ }^{27}$ They observed even seven times higher accumulation of iron in atherosclerotic lesions than in the adjacent arterial wall. In advanced carotid lesions in humans, 3.3-fold higher iron content was detected. ${ }^{13}$ However, in apoE-deficient mice there was much smaller content of iron in the aortic wall than in other examined organs. ${ }^{22}$ The observed discrepancies can be explained by different models of atherosclerosis used in these studies. Although lower than in surrounding tissues, the concentration of iron in atheromas in apoE/LDLR ${ }^{-/-}$mice might be high enough to trigger oxidative events. Hemoglobin released from the phagocytosed erythrocytes may contribute, at least partially, to iron deposition in atherosclerotic lesions. ${ }^{28}$ Furthermore, free ferrous ions $\left(\mathrm{Fe}^{2+}\right)$ in presence of hydrogen peroxide have a strong catalytic power to generate highly reactive hydroxyl radicals (Fenton's reaction). The oxidation state of the iron might be indicative of yielding active radical species. Recently, x-ray absorption near-edge structure (XANES) setup was successfully used to study the oxidation state of iron in cancerous and noncancerous prostate tissues. ${ }^{29}$ This technique can also be applied to study atherosclerosis.

Cupric ions $\left(\mathrm{Cu}^{2+}\right)$ were shown to induce formation of lipid peroxides with or without presence of hydrogen peroxide. ${ }^{30}$ Copper-mediated peroxidation of LDL involves not only lipids but also apolipoproteins. ${ }^{31}$ Copper bound to ceruloplasmin was also reported to promote LDL oxidation. ${ }^{32}$ In DNA microarray studies, copper increased the expression of seven cholesterologenic genes by cultured human macrophages. ${ }^{33}$ On the other hand, copper is a component of $\mathrm{Cu}-\mathrm{Zn}$ superoxide dismutase, the enzyme being involved in free radical breakdown. In the present study, copper was seen in high amounts only in myocardium. It was recently shown, as compared to other tissues, that heart exhibits the highest concentration of this element. ${ }^{14}$ Very low concentration of copper ( $<2 \mathrm{ug} / \mathrm{g})$ in atherosclerotic plaques in apoE/LDLR ${ }^{-/-}$mice may suggest its minor role in metalinduced oxidation of LDL molecules. Recently, identical conclusion was formulated by Rajendran and coworkers. ${ }^{34}$ In rabbits fed on a cholesterol-rich diet, they found two times lower concentration of copper in atheromas than in the unaffected artery walls (1.9 vs $4.1 \mathrm{ppm}$ ).

Despite their influence on LDL, iron and copper ions can be involved in modification and reorganization of extracellular matrix components. Fragmentation and significant loss of proline in collagen was observed in the presence of $\mathrm{Cu}^{2+}$ and hydrogen peroxide. ${ }^{35}$ The action of metal ions can also be indirect through activation of matrix-degrading enzymes, matrix metalloproteinases (MMPs). In apoE-deficient mice fed with a low-iron diet, lower expression of MMP-9 and higher collagen content in lesions were observed. ${ }^{36}$ Oxidation of matrix macromolecules may enhance their decomposition by proteolytic enzymes. ${ }^{37}$ Matrix degradation can be followed by lesion rupture and occlusion of the vessel. In the present study, very high amounts of collagen fibers and 
intimal smooth muscle cells in 'fibrous cap' were observed, reflecting relative plaque stability.

Zinc is a water-soluble trace element that also acts as a cofactor of superoxide dismutase and has an antioxidant role in several oxidative processes including atherogenesis. ${ }^{38,39}$ Zinc deficiency increases plasma lipids and atherosclerotic markers. ${ }^{40}$ It was shown that early lesion formation may be accelerated by free radical production caused by increased iron levels and that zinc might antagonize such effect. ${ }^{41}$ Rabbits fed a high-cholesterol diet with zinc supplementation displayed milder atherosclerosis than animals treated with no supplementation. ${ }^{42}$ Surprisingly, there was no difference in zinc concentrations in atherosclerotic lesions of zincfed animals compared to controls. In our study, zinc was observed in moderately low concentrations in lipid and macrophage-containing areas. Higher concentrations of zinc were seen in muscles and in mineral concretions. Using a proton microprobe, zinc was detected in inorganic deposits in human aortas and it was proposed that zinc ions are adsorbed on the surface of mineral concretions.

Vascular calcifications are increasingly recognized as a significant contributor to cardiovascular morbidity and mortality as well as a biologically regulated process potentially subject to prevention and reversal. ${ }^{43}$ The deposition of hydroxyapatite in the innominate arteries of apoE-knockout mice is mediated by chondrocyte-like cells, suggesting that the mechanism of calcification may in part recapitulate the process of endochondral bone formation. ${ }^{44}$ However, the presence of cartilage matrix components (collagen type 2) and intense calcifications were investigated in older animals (45-104 weeks of age). Osteoprotegerin (OPG), a member of the tumor necrosis factor superfamily, plays an important role in bone remodeling and is expressed in both mouse and human atherosclerotic lesions. OPG inhibits advanced plaque progression by preventing an increase in lesion size and lesion calcification and may act as a survival factor modulating MMP-9 production in vascular cells. ${ }^{45}$ Atorvastatin treatment showed a strong reduction of cholesterol and calcium salts accumulation in aortas of apoE-deficient mice fed with a high-lipid/high-cholesterol diet. ${ }^{12}$ In our study, there was a high content of calcium in aortic plaque areas occupied by lipids and macrophages. Since we used relatively young animals ( 24 weeks old), we did not observe cells of chondrocyte-like morphology, and faint alcian blue staining indicated that there was no formation of cartilage matrix. Very high concentration of calcium was observed in mineral deposits and $\mathrm{Ca} / \mathrm{P}$ proportion in these deposits varied, suggesting presence of different minerals in the analyzed lesions. $\mathrm{Ca} / \mathrm{P}$ ratio of around 2 indicates the presence of hydroxyapatite salts, whereas in other locations with $\mathrm{Ca} / \mathrm{P}$ $>2$ (up to 6.83) calcium salts, other than hydroxyapatite, could be found (e.g. carbonates, lactates). Similar mineralization patterns were reported in human homograft aortic valves. $^{46}$

Similar distribution was also characteristic to phosphorus, however, its concentration in calcifications was not as high as it was in the case of calcium. In fatty streaks of atherosclerotic lesions, phosphorus is also abundant in phospholipids. Chronic renal failure, usually accompanied by high serum phosphates level, accelerates both atherosclerosis and arterial calcification in apoE-knockout mice. ${ }^{47}$ The novel phosphate binder, sevelamer, has been shown to prevent the progression of aortic and coronary calcification in uremic mice. $^{48}$

Strontium was observed in mineral deposits of human aorta and its concentration strongly correlated $(r>0.9)$ with calcium concentration. ${ }^{49}$

As regards sulphur, macrophage glutathione content and glutathione peroxidase activity are inversely related to cellmediated oxidation of LDL. ${ }^{50,51}$ On the other hand, methionine intake has the atherogenic effect. ${ }^{52}$ In our observations, there was rather weak content of sulphur in atheromas and its presence was detected predominantly in cells. Sulphur, being an essential element present in methionine and cysteine, is a natural component of proteins. Low content of matrix proteoglycans in atherosclerotic lesions, as demonstrated by weak alcian blue staining, can correspond with relatively low concentration of extracellular sulphur since sulphate residues are numerous in glycosaminoglycans forming matrix proteoglycans.

Potassium and chloride are common ions of intracellular occurrence. They were displayed as typical components and markers of cell-rich areas and they were considered as tissue structure tracers. ${ }^{53}$

In summary, micro-XRF spectrometry was shown to be an efficient tool for evaluation of atherosclerotic plaque elemental content. The use of this method provides a novel insight into the morphological and physicochemical properties of the atherosclerotic plaques and may be used in further investigations aimed at characterization of the effects of pharmacological and dietary treatment on elemental content of atherosclerotic plaques in apoE/LDLR ${ }^{-/-}$mice.

\section{Acknowledgements}

This report summarizes data obtained during realization of Hasylab/DESY project II-20060048 EC. The project was supported by Contract RII3-CT-2004-506008 (IA-SFS) of the EU Commission. The project was supported by Contract RII3-CT-2004-506008 (IA-SFS) of the EU Commission and project K/ZDS/000685 from Scientific Council of Jagiellonian University Medical College to M.G.

\section{REFERENCES}

1. Lusis AJ. Nature 2000; 407: 233.

2. Hansson GK. N. Engl. J. Med. 2005; 352: 1685.

3. Jawien J, Nastalek P, Korbut R. J. Physiol. Pharmacol. 2004; 55: 503.

4. Ishibashi S, Herz J, Maeda N, Goldstein JL, Brown MS. Proc. Natl. Acad. Sci. U.S.A. 1994; 91: 4431.

5. Witting PK, Pettersson K, Ostlund-Lindqvist AM, Westerlund C, Eriksson AW, Stocker R. FASEB J. 1999; 13: 667.

6. Kwiatek WM, Banas A, Gajda M, Galka M, Pawlicki B, Falkenberg G, Cichocki T. J. Alloys Compd. 2005; 401: 173.

7. Szczerbowska-Boruchowska M, Lankosz M, Ostachowicz J, Adamek D, Krygowska-Wajs A, Tomik B, Szczudlik A, Simonovici A, Bohic S. X-Ray Spectrom. 2004; 33: 3.

8. Jin H, Ham K, Chan JY, Butler LG, Kurtz RL, Thiam S, Robinson JW, Agbaria RA, Warner IM, Tracy RE. Phys. Med. Biol. 2002; 47: 4345.

9. Nicoletti A, Kaveri S, Caligiuri G, Bariety J, Hansson GK. J. Clin. Invest. 1998; 102: 910.

10. Jawien J, Gajda M, Rudling M, Mateuszuk L, Olszanecki R, Guzik TJ, Cichocki T, Chlopicki S, Korbut R. Eur. J. Clin. Invest. 2006; 36: 141. 
11. Vekemans B, Janssens K, Vincze L, Adams F, van Espen P. X-Ray Spectrom. 1994; 23: 278.

12. van De Poll SW, Romer TJ, Volger OL, Delsing DJ, Bakker Schut TC, Princen HM, Havekes LM, Jukema JW, van Der Laarse A, Puppels GJ. Arterioscler. Thromb. Vasc. Biol. 2001; 21: 1630.

13. Stadler N, Lindner RA, Davies MJ. Arterioscler. Thromb. Vasc. Biol. 2004; 24: 949.

14. Zhang ZY, Liu NQ, Li FL, Zhang J, Zhu H, Qin C, Zou ZY, Tang XW. X-Ray Spectrom. 2006; 35: 253.

15. Jawien J, Csanyi G, Gajda M, Mateuszuk L, Lomnicka M, Korbut R, Chlopicki S. Eur. J. Pharmacol. 2007; 556: 129.

16. Olszanecki R, Jawien J, Gajda M, Mateuszuk L, Gebska A, Korabiowska M, Chlopicki S, Korbut R. J. Physiol. Pharmacol. 2005; 56: 627.

17. Heinecke JW. Atherosclerosis 1998; 141: 1.

18. Kartikasari AE, Georgiou NA, de Geest M, Kats-Renaud JH, Bouwman JJ, van Asbeck BS, Marx JJ, Visseren FL. Eur. J. Clin. Invest. 2006; 36: 743.

19. Holvoet P, Collen D. FASEB J. 1994; 8: 1279.

20. Fuhrman B, Oiknine J, Aviram M. Atherosclerosis 1994; 111: 65.

21. Minqin R, Rajendran R, Pan N, Tan BK, Ong WY, Watt F, Halliwell B. Free Radic. Biol. Med. 2005; 38: 1206.

22. Tous M, Ferre N, Vilella E, Riu F, Camps J, Joven J. Metabolism 2004; 53: 95

23. Heinecke JW, Rosen H, Chait A. J. Clin. Invest. 1984; 74: 1890.

24. Pratico D, Pasin M, Barry OP, Ghiselli A, Sabatino G, Iuliano L, Fitzgerald GA, Violi F. Circulation 1999; 99: 3118.

25. Lee TS, Shiao MS, Pan CC, Chau LY. Circulation 1999; 99: 1222.

26. Kirk EA, Heinecke JW, LeBoeuf RC. J. Clin. Invest. 2001; 107: 1545.

27. Thong PS, Selley M, Watt F. Cell. Mol. Biol. 1996; 42: 103.

28. Lee TS, Lee FY, Pang JH, Chau LY. Chin. J. Physiol. 1999; 42: 17.

29. Kwiatek WM, Banas A, Banas K, Gajda M, Galka M, Falkenberg G, Cichocki T. J. Alloys Compd. 2005; 401: 178.

30. Lynch SM, Frei B. J. Biol. Chem. 1995; 270: 5158.

31. Wagner P, Heinecke JW. Arterioscler. Thromb. Vasc. Biol. 1997; 17: 3338.

32. Ehrenwald E, Chisolm GM, Fox PL. J. Clin. Invest. 1994; 93: 1493.

33. Svensson PA, Englund MC, Markstrom E, Ohlsson BG, Jernas M, Billig H, Torgerson JS, Wiklund O, Carlsson LM, Carlsson B. Atherosclerosis 2003; 169: 71.

34. Rajendran R, Ren M, Ning P, Tan Kwong HB, Halliwell B, Watt F. Biochem. Biophys. Res. Commun. 2007; 353: 6.
35. Kato Y, Uchida K, Kawakishi S. J. Biol. Chem. 1992; 267: 23646.

36. Lee HT, Chiu LL, Lee TS, Tsai HL, Chau LY. J. Biomed. Sci. 2003; 10: 510 .

37. Mattana J, Margiloff L, Chaplia L. Free Radic. Biol. Med. 1999; 27: 315.

38. Hennig B, Toborek M, Mcclain CJ. Nutrition 1996; 12: 711.

39. Paul A, Calleja L, Joven J, Vilella E, Ferre N, Camps J, Girona J, Osada J. Int. J. Vitam. Nutr. Res. 2001; 71: 45.

40. Reiterer G, MacDonald R, Browning JD, Morrow J, Matveev SV, Daugherty A, Smart E, Toborek M, Hennig B. J. Nutr. 2005; 135: 2114.

41. Minqin R, Watt F, Huat BT, Halliwell B. Free Radic. Biol. Med. 2003; 34: 746.

42. Ren M, Rajendran R, Ning P, Tan Kwong HB, Choon NO, Watt F, Jenner A, Halliwell B. Free Radic. Biol. Med. 2006; 41: 222.

43. Bostrom K, Demer LL. Crit. Rev. Eukaryot. Gene Expr. 2000; 10: 151.

44. Rattazzi M, Bennett BJ, Bea F, Kirk EA, Ricks JL, Speer M, Schwartz SM, Giachelli CM, Rosenfeld ME. Arterioscler. Thromb. Vasc. Biol. 2005; 25: 1420.

45. Bennett BJ, Scatena M, Kirk EA, Rattazzi M, Varon RM, Averill M, Schwartz SM, Giachelli CM, Rosenfeld ME. Arterioscler. Thromb. Vasc. Biol. 2006; 26: 2117.

46. Lis GJ, Rokita E, Podolec P, Pfitzner R, Dziatkowiak A, Cichocki T. J. Heart Valve Dis. 2003; 12: 741.

47. Massy ZA, Ivanovski O, Nguyen-Khoa T, Angulo J, Szumilak D, Mothu N, Phan O, Daudon M, Lacour B, Drueke TB, Muntzel MS. J. Am. Soc. Nephrol. 2005; 16: 109.

48. Phan O, Ivanovski O, Nguyen-Khoa T, Mothu N, Angulo J, Westenfeld R, Ketteler M, Meert N, Maizel J, Nikolov IG, Vanholder R, Lacour B, Drueke TB, Massy ZA. Circulation 2005; 112: 2875.

49. Rokita E, Cichocki T, Heck D, Jarczyk L, Kunz J, Strzalkowski A. Trace Elem. Med. 1989; 6: 158.

50. Heinecke JW, Rosen H, Suzuki LA, Chait A. J. Biol. Chem. 1987; 262: 10098.

51. Rosenblat M, Aviram M. Free Radic. Biol. Med. 1998; 24: 305.

52. Troen AM, Lutgens E, Smith DE, Rosenberg IH, Selhub J. Proc. Natl. Acad. Sci. U.S.A. 2003; 100: 15089.

53. Kwiatek WM, Hanson AL, Paluszkiewicz C, Galka M, Gajda M, Cichocki T. J. Alloys Compd. 2004; 362: 83. 